\title{
EFFECTS OF LEAF DAMAGE BY APPLE LEAFCURLING MIDGE (DASYNEURA MALI) ON PHOTOSYNTHESIS OF APPLE LEAVES
}

\author{
P.A. ALLISON, J.S. MEEKINGS, A.R. TOMKINS and D.J. WILSON
}

The Horticultural \& Food Research Institute of New Zealand Ltd Ruakura Research Centre, Private Bag 3123, Hamilton

\section{ABSTRACT}

The effect of damage by apple leafcurling midge (Dasyneura mali) on photosynthesis by apple cv. 'Braeburn' leaves was investigated. A trial in the Waikato, measured photosynthesis of healthy and apple leafcurling midge damaged leaves of similar size and age. The rate of photosynthesis was not altered when there was less than $60 \%$ of the leaf area lost due to damage. In a second trial at Havelock North, all the leaves on a tree were assessed for apple leafcurling midge damage as well as their length and area. A relationship between leaf length and area for undamaged leaves was found and used to estimate that damaged leaves lost an average of $33 \%$ of their area. Leaf damage by apple leafcurling midge to the Havelock North tree reduced carbon acquisition by $51.6 \mathrm{mg}$ every hour.

Keywords: apple, apple leafcurling midge, Dasyneura mali, photosynthesis, leaf damage

\section{INTRODUCTION}

Apple leafcurling midge (ALM) (Dasyneura mali) used to be regarded as a secondary pest causing low levels of leaf damage in commercial apple orchards in New Zealand. However, in recent years the incidence of ALM in some orchards has risen substantially, with a recent survey revealing up to $41 \%$ of leaves damaged and $2 \%$ of fruit contaminated by this pest (Tomkins et al. 1994).

Apple leafcurling midge can affect apple production in a number of different ways including; contamination of fruit by pupal cocoons; larval damage to flowers causing deformed fruit; larval damage to current season leaves causing reductions in photosynthesis and amount of leaf area available for photosynthesis. The latter effects may, in turn, reduce yield as shown for pear leafcurling midge (Dasyneura pyri) (Kolbe 1972) and other leaf-feeding apple pests (Baker 1983; Reissig et al. 1982). These effects need to be quantified as the basis for developing action thresholds for ALM management.

This paper reports a study measuring the effect of ALM on the photosynthesis of individual leaves and leaf area losses due to the pest.

\section{Trial 1}

\section{MATERIALS AND METHODS}

Photosynthesis measurements were made between 21 and 25 November 1994 on a commercial block of six year-old apple cv. 'Braeburn' trees on M106 Rootstock at Matangi, Waikato. Damaged leaves were chosen from within two rows on the western side of the block. The damaged leaves were chosen so that the estimated amount of leaf area lost due to ALM damage ranged from 10 to $80 \%$. Each damaged leaf was paired with an undamaged leaf of similar age and length, located as close as possible to the damaged leaf. All leaves were in exposed parts of the tree and between 1.0 and $1.5 \mathrm{~m}$ above the ground. 
In total 26 pairs of leaves were chosen (52 leaves total). All leaves had their photosynthesis rate measured with a WALZ portable microcuvette infrared gas analyser using standard conditions of 1430 PAR irradiance, $20^{\circ} \mathrm{C}$ air temperature and $80 \%$ humidity. Leaf area was measured using a LiCor LI-3000 portable leaf area machine. The percent of leaf area lost due to ALM damage was estimated by comparing the actual leaf area to an estimate of the area the leaf would have had if it was not damaged. This estimated area was obtained by tracing around the undamaged section and extending it to the rest of the leaf.

Trial 2

In a separate trial at Havelock North every leaf was harvested from an apple tree cv. 'Braeburn' and the leaf length and the presence of ALM damage were recorded. Damage was scored as slight (only part of one side of the leaf rolled), moderate (either slight rolling on both sides of the leaf or about half of one side rolled) or severe (more than half of one side rolled). All damaged leaves had their area measured using a LiCor LI-3000 portable area machine. In addition, the area of 450 healthy leaves was measured in order to provide a calibration between leaf length and area. The regression line from this calibration was used to estimate what the area of the damaged leaves would have been if they were not damaged.

Trial 1

\section{RESULTS AND DISCUSSION}

There were only two points with more than $60 \%$ of their area lost. These two points, are shown as open symbols in Figure 1 but have been excluded from any analysis because there are only two of them and they completely dominate any analysis. Healthy leaves had an average photosynthesis rate of 10.5 (range 7.0 to 14.6) $\mu \mathrm{mol} \mathrm{CO} / \mathrm{CO}_{2} / \mathrm{s}$ which is within the range $(6.3$ to 22.1$)$ found by most previous researchers for healthy apple leaves (Barden 1978). Figure 1 shows the difference between the photosynthetic rate of each damaged leaf and its associated undamaged leaf. The slope of a regression line fitted to this data is 0.052 . This slope is not significantly different from zero $(\mathrm{P}=0.25)$. This means that for leaves with less than $60 \%$ of their leaf area lost due to photosynthesis there was an effect on the actual photosynthetic rate of the leaf remaining. It does appear that at levels of leaf damage higher than $60 \%$ there is a reduction in the photosynthesis of leaves. Unfortunately there were only two leaves with this level of damage so no conclusions can be drawn from them.

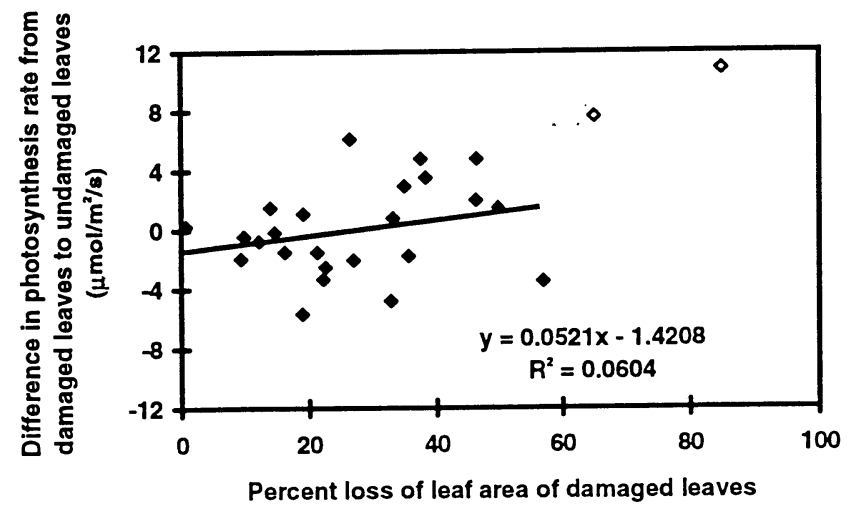

FIGURE 1: The difference in photosynthetic rate $\left(\mu \mathrm{mo1} \mathrm{CO}_{2} / \mathrm{m}^{2} / \mathrm{s}\right)$ between damaged and comparable undamaged apple cv. 'Braeburn' leaves as related to the amount of leaf area that the damaged leaves have lost. 
Proctor et. al. (1982) found reductions in the photosynthesis rate of leaves where there have been only three mines per leaf. In this case the leafminers were found to reduce the amount of chlorophyll in the leaf part they are mining. At the time this trial was done all of the ALM damage present in the block was quite fresh. As a result the leaves, including the rolled section, were still green and in reasonable condition. It seems unlikely that at this stage there is any reduction in the chlorophyll content of the leaf. When ALM damage gets older the leaves tend to dry up and become brittle. Under these circumstances it is expected that there would be a reduction in the chlorophyll content of the leaves and thus a reduction in the photosynthesis of the leaves. Further work is needed to confirm this point.

Although the photosynthetic rate of leaves is unaffected by ALM damage, this does not take into account the reduction in the area of the damaged leaves. A leaf that has lost $50 \%$ of its area due to ALM, although producing the same amount of photosynthate per $\mathrm{m}^{2}$, will only be producing half the amount on a per leaf basis. Trial 2

The relationship between the length $(\mathrm{L})$ and area (A) of healthy, undamaged leaves at Havelock North is shown in Figure 2 and was best described by the linear equation; $A=0.34 L-4.64\left(R^{2}=0.86\right)$

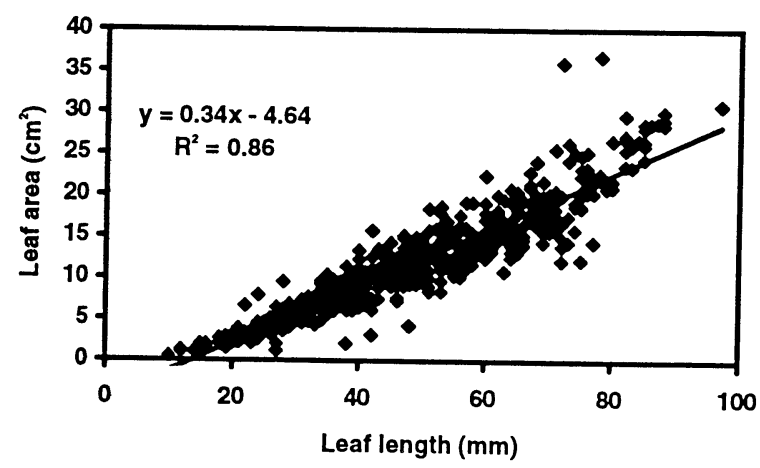

FIGURE 2: Relationship between leaf length and leaf area for undamaged apple cv. 'Braeburn' leaves.

TABLE 1: Actual area of apple leafcurling midge damaged leaves and estimated area of those leaves if they had remained undamaged.

\begin{tabular}{lcccc}
$\begin{array}{l}\text { Damage } \\
\text { severity }\end{array}$ & $\begin{array}{c}\text { Number } \\
\text { of leaves }\end{array}$ & $\begin{array}{c}\text { Actual average } \\
\text { leaf area } \\
\left(\mathrm{cm}^{2}\right)\end{array}$ & $\begin{array}{c}\text { Estimated average } \\
\text { undamaged leaf } \\
\text { area }\left(\mathrm{cm}^{2}\right)\end{array}$ & $\begin{array}{c}\text { Percent loss } \\
\text { of leaf } \\
\text { area }\end{array}$ \\
\hline Slight & 124 & 11.8 & 14.0 & 15.7 \\
Moderate & 85 & 8.6 & 13.0 & 33.8 \\
Severe & 83 & 3.1 & 9.8 & 68.4 \\
Overall & 292 & 8.4 & 12.5 & 32.8 \\
\hline
\end{tabular}

This equation was used to estimate the amount of leaf area on the tree that was lost due to ALM damage (Table 1). It is seen that for this tree, ALM damaged leaves had on average lost $33 \%$ of their area. On this tree that results in a loss of $0.12 \mathrm{~m}^{2}$ of leaf. Assuming a photosynthesis rate of $10 \mu \mathrm{mol} \mathrm{CO} 2 / \mathrm{m}^{2} / \mathrm{s}$ this tree would lose photosynthesising $4.3 \mathrm{mmol} \mathrm{CO} 2$ every hour. Every mole of $\mathrm{CO}_{2}$ contains $12 \mathrm{~g}$ of carbon. This means that the accumulation of $51.6 \mathrm{mg}$ of carbon is lost every hour. 
The tree used in the study at Havelock North had 7\% of its leaves damaged by ALM which is a very low level of damage judging by the results of an earlier survey (Tomkins et al. 1994). On other trees, where damage is greater, there is the potential for the tree to miss out on a large amount of carbon accumulation. How that loss of leaf area affects the production of a tree over time needs further investigation.

\section{CONCLUSIONS}

Apple leafcurling midge does not reduce the photosynthetic rate of apple leaves, where less than $60 \%$ of the leaf area has been lost due to damage. The insect does however reduce the amount of carbon accumulation by the tree due to the amount of leaf area that is lost. Our future studies aim to investigate the effect of leaf damage by ALM on the sustainable yield of mature apple trees.

\section{ACKNOWLEDGEMENTS}

We wish to thank ENZA New Zealand for funding; Mike Dowling from Alderwood orchard for the use of trees and his co-operation during this study and Barbara Dow for assistance with the statistical analysis of the data.

\section{REFERENCES}

Baker, R.T., 1983. Effect of European red mite (Panonychus ulmi) on quality and yield of apples. 10th Int. Congress of Plant Protection Vol. 1: 108.

Barden, J.A., 1978. Apple leaves, their morphology and photosynthetic potential. HortScience 13: 644-646.

Kolbe, W., 1972. Occurrence and control of pear leaf-curling midge and apple leafcurling midge. Pflanzenschutz-Nachrichten Bayer 35: 291-308.

Proctor, J.T.A., Bodnar, J.M., Blackburn, W.J. and Watson, R.L., 1982. Analysis of the effects of the spotted tentiform leafminer (Phyllonorycter blancardella) on the photosynthetic characteristics of apple leaves. Can. J. Botany 60: 2734-2740.

Reissig, W.H., Weires, R.W., and Forshey, C.G., 1982. Effects of gracillarid leafminers on apple tree growth and production. Env. Ent. 11: 958-963.

Tomkins, A.R., Wilson, D.J., Hutchings, S.O. and June, S., 1994. A survey of apple leafcurling midge (Dasyneura mali) management in Waikato orchards. Proc 47th N.Z. Plant Protection Conf:: 346-349 